\title{
Influence of coral symbionts on feeding preferences of crown-of-thorns starfish Acanthaster planci in the western Pacific
}

\author{
Morgan S. Pratchett* \\ Department of Marine Biology, James Cook University, Townsville, Queensland 4811, Australia
}

\begin{abstract}
The crown-of-thorns starfish Acanthaster planci (L.) is well adapted to feed on a wide range of different corals, but often exhibits striking preference for a small suite of available prey species. Numerous theories have been forwarded to explain its feeding preferences, but many of these theories have not been tested. In this study, I test whether coral symbionts significantly affect the feeding preferences of crown-of-thorns starfish by removing symbionts from replicate colonies of 6 different coral species. Crown-of-thorns starfish had a clearly defined hierarchy of preference for the 6 different corals when these contained symbionts (Acropora gemmifera $>$ A. nasuta $=$ A. loripes $>$ Seriatopora hystrix > Pocillopora damicornis > Stylophora pistillata). However, when coral symbionts were removed, then the starfish readily consumed all 6 corals and did not exhibit any significant selectivity. Further manipulation of symbiont assemblages showed that the trapeziid crabs (Tetralia and Trapezia species) were the most effective of the various coral symbionts in deterring starfish from feeding on their host colony. Moreover, those corals that were least preferred by crownof-thorns starfish contained the largest and most powerful species of Trapezia ( $T$. cymodoce), whereas the most preferred corals contained only very small Tetralia spp. crabs. Further experimentation is required to assess the generality of these results, but for the 6 coral species tested, it is clear that coral symbionts (and particularly trapeziid crabs) do have a marked influence on the feeding preferences of the crown-of-thorns starfish.
\end{abstract}

KEY WORDS: Acropora $\cdot$ Host defence $\cdot$ Pocilloporidae $\cdot$ Prey selection $\cdot$ Symbiosis $\cdot$ Trapeziidae

\section{INTRODUCTION}

Outbreaks of the crown-of-thorns starfish Acanthaster planci (L.) represent the most significant biological disturbance on tropical coral reefs throughout much of the Indo-Pacific region. Aside from their potential to cause widespread coral destruction (e.g. Guam: Chesher 1969; Great Barrier Reef: Pearson \& Endean 1969; Japan: Yamaguchi 1986), selective feeding by $A$. planci causes differential mortality among coral species and can exert a major influence on coral

\footnotetext{
*E-mail: morgan.pratchett@jcu.edu.au
}

community structure. In the eastern Pacific, Glynn $(1974,1976)$ found crown-of-thorns starfish fed mostly on rarer coral species, increasing the dominance of the abundant coral species, Pocillopora damicornis (see also Branham et al. 1971). Elsewhere, A. planci tend to feed mostly on relatively abundant coral species (e.g. Acropora spp. and Montipora spp.) and thereby increase the prevalence of non-preferred corals (e.g. Ormond et al. 1976, Colgan 1987, Keesing 1993, De'ath \& Moran 1998).

Acanthaster planci is adapted to feed on a wide range of different corals, and it is not known why they consistently target a small suite of available prey species. In general, A. planci appears to favour corals 
of the family Acroporidae (see reviews by Potts 1981, Moran 1986, Birkeland \& Lucas 1990). However, Moran (1986) and more recently De'ath \& Moran (1998) have pointed out that few studies of the feeding habits of A. planci have employed methodologies necessary to determine feeding preference (see also Potts 1981). Most studies compare the proportion of a particular coral eaten to its proportional availability at the community or reef level (e.g. Branham et al. 1971, Glynn 1974, Keesing 1993). Such studies clearly show that $A$. planci are very selective in their choice of prey, but often fail to identify the actual prey species which are preferred. Identifying preferred prey in the field is difficult because feeding preferences are confounded by differences in the relative size, abundance and accessibility of different corals (De'ath \& Moran 1998).

General models of optimal diet theory predict that Acanthaster planci chooses prey which maximise energetic return (Ormond et al. 1976). However, Keesing (1990) explored the relationship between the nutritional value of corals and prey preferences of A. planci, and although the most highly preferred corals (e.g. Acropora spp.) had the highest energy content, feeding preferences were not altogether consistent with theoretical predictions of optimal foraging. Principally, non-preferred corals from the family Faviidae had similar nutritional value to preferred acroporid corals (Keesing 1990). In reviewing feeding habits of $A$. planci, Potts (1981) suggested that coral prey which are readily consumed by $A$. planci may represent the least avoided species, rather than those which are most actively sought. Defensive mechanisms of scleractinian corals, including nematocysts, mesenterial filaments, secondary metabolites, and the antagonostic behaviour of coral symbionts, all may deter starfish from feeding on certain corals (Potts 1981). In the best documented example, Glynn $(1974,1976)$ showed that coral symbionts attack $A$. planci and deter it from feeding on pocilloporid corals. This research, conducted in the eastern Pacific, showed that coral symbionts were the main reason why common pocilloporid corals were under-represented in the diet of $A$. planci.

Although it has never been explicitly tested, coral symbionts are thought to have comparatively little influence on the feeding habits of Acanthaster planci in the western Pacific (particularly on the Great Barrier Reef). This theory came about because both Pocillopora and Stylophora species, which both contain highly agnostic coral symbionts, are among the most highly preferred coral prey of $A$. planci on the Great Barrier Reef (e.g. Keesing 1990, De'ath \& Moran 1998). The purpose of the present study was to test whether coral symbionts do influence the feeding preferences of crown-of-thorns starfish on the Great Barrier Reef. The influence of coral symbionts was tested by examining feeding preferences of $A$. planci for various corals with their symbionts removed and comparing feeding preferences of starfish for the same corals which contained symbionts. Further manipulative experiments were also conducted to assess the relative efficacy with which different symbiont taxon deter A. planci from feeding on their respective host colonies.

\section{METHODS}

Feeding trials. Feeding preferences of Acanthaster planci were examined during feeding trials conducted in large tanks at Lizard Island $\left(14^{\circ} 40^{\prime} \mathrm{S}, 145^{\circ} 27^{\prime} \mathrm{E}\right)$, on the northern Great Barrier Reef (GBR), Australia. Feeding trials were conducted using 6 coral species from 2 different families (Acroporidae: Acropora gemmifera, A. nasuta and A. loripes; and Pocilloporidae: Seriatopora hystrix, Pocillopora damicornis and Stylophora pistillata). Both Acropora spp. and pocilloporid corals were used because of known differences in their symbiotic fauna (e.g. Garth 1964). However, the particular coral species were selected during a $3 \mathrm{~d}$ preliminary investigation of symbiotic fauna among 42 species of tightly branching scleractinian coral. The 6 coral species selected were highly abundant, easily collected, and nearly always occupied by coral symbionts.

To conduct feeding experiments, 40 small (900 to $1200 \mathrm{~cm}^{3}$ ) colonies of each of the 6 coral species (Acropora gemmifera, A. nasuta, A. loripes, Seriatopora hystrix, Pocillopora damicornis and Stylophora pistillata) were collected from within the Lizard Island lagoon and then transported to the Lizard Island research station. All coral colonies were collected and transported in separate containers in order to ensure they retained their coral symbionts. Two colonies of each coral species were then arranged haphazardly in each of 20 large (1.1 m diameter) circular tanks, giving a total of 12 coral colonies per tank. To test the influence of coral symbionts on feeding preferences of Acanthaster planci, symbionts were removed from all coral colonies in half (10 of 20) of the tanks. Symbionts were removed using plastic forceps, and then fixed in $5 \%$ seawater formalin for identification. Symbionts within coral colonies in the remaining 10 tanks (the control tanks) were identified in situ prior to the experiment, but then removed at the termination of the experiment to confirm species identification.

Twenty-four hours after the corals were collected, a period which allowed both the corals and their symbionts to acclimatise, crown-of-thorns starfish of approximately equal size $(36 \mathrm{~cm} \pm 1.3 \mathrm{SE}$ total diameter) were introduced into each of the 20 coral tanks. To counter potential differences in the recent feeding his- 
tory of the individual starfish, they had been held for $5 \mathrm{~d}$ without food before being used in the feeding trials, following Keesing (1990). At the start of the feeding trials, a single starfish was placed directly in the centre of each tank and observations were then made every 3 to $4 \mathrm{~h}$ for a total of $10 \mathrm{~d}$ to determine the sequence in which coral colonies were consumed. The experiment was terminated after $10 \mathrm{~d}$ to ensure that the experiment was ended before corals and their symbionts began to suffer the effects of captivity. Few colonies (at most 3 in 1 tank) were uneaten after this period.

Analysing feeding preference. Analyses of feeding preferences of Acanthaster planci were based on the order in which coral colonies were consumed. Every coral colony within each of the tanks was assigned a rank (from 1 to 12) according to the order in which it was eaten. All colonies that were not eaten at the end of the experiment (after $10 \mathrm{~d}$ ) were given an equal rank equal to the mean of remaining ranks (i.e. when 2 out of 12 colonies were left they were both given a rank score of 11.5). Where starfish feed selectively, then preferred prey species would have significantly lower ranks than less preferred species. To analyse differences in the ranks for each coral species, I used Friedman's test, which compares the mean ranks of each coral species across all replicate tanks $(n=10)$. These analyses were carried out separately for the control tanks (symbionts removed) and the experimental tanks (symbionts retained). Where there were significant differences in the mean ranks among coral species, this indicated that starfish were feeding selectively.

Separate analyses, using Kendall's coefficient of concordance $(W)$, were carried out to test that the patterns of prey preference were consistent among starfish in separate tanks. Kendall's coefficient of concordance was used firstly to test for differences in feeding preferences of Acanthaster planci across all control and experimental tanks (following Zar 1984). Where there was a significant difference across all tanks $(n=20)$, I then tested whether there were significant differences among control tanks $(n=10)$, and among experimental tanks $(\mathrm{n}=10)$. If symbionts had a significant influence on the feeding preferences of starfish, I would expect significant differences across experimental and control tanks, but concordance (no difference in the feeding preferences of starfish) among control tanks and among experimental tanks.

Coral symbionts. Differences in the symbiont assemblages of the 6 coral species were analysed to assess whether variation in the symbiont fauna reflected differences in the feeding preferences of Acanthaster planci. Symbiont assemblages of the 6 coral species were described using the 40 colonies of each coral species that were collected for use in the aforementioned feeding trials. Variation in symbiont assemblages was analysed using multivariate analysis of variance (MANOVA), which simultaneously compared the abundance of all symbiont taxon among the 6 coral species. Where there were significant differences in the symbiont assemblages of the 6 coral species, I used canonical discriminate analysis (CDA) to show the relative similarity of symbiont assemblages from each coral species. To assist with interpretation of the CDA, structural coefficients of the most significant response variables were plotted as vectors, which identify the symbionts that are primarily responsible for differences between each coral species.

Manipulating symbionts. To compare the efficacy with which symbionts deter Acanthaster planci from feeding on their host corals, further feeding trials were conducted in which I modified the symbiont composition in replicate coral colonies. In each of 20 large circular tanks, I placed a total of 10 coral colonies (all of the same species and of approximately equal size). I then selected colonies at random and modified their symbiont assemblages, so that there were 2 colonies in each tank that were subject to each of 5 different experimental regimes: (1) no symbionts, (2) gobies only, (3) shrimps only, (4) crabs only, and (5) gobies, shrimps, and crabs. All colonies used in the experiment were collected from the Lizard Island lagoon and transported back to the research station in separate containers to maintain their symbiont assemblages.

Twenty-four hours after the experiment had been set up, a single crown-of-thorns starfish (ca $36 \mathrm{~cm} \pm 1.3 \mathrm{SE}$ total diameter), which had been starved for $5 \mathrm{~d}$, was placed in the centre of each tank. The subsequent order in which coral colonies were consumed was recorded over a period of $10 \mathrm{~d}$. These trials were conducted using Pocillopora damicornis and Acropora nasuta in 10 replicate tanks with each coral species. Feeding preferences of Acanthaster planci were analysed by comparison of combined ranks for colonies in each treatment, using Friedman's test (described above). I then tested whether feeding preferences of $A$. planci were consistent between the 2 coral species, and across replicate tanks using Kendall's coefficient of concordance (described above).

\section{RESULTS}

\section{Coral symbionts}

A total of 18 symbiont taxa were recorded across the 240 coral colonies examined. These included 3 species of Tetralia, 4 species of Trapezia, 5 different species of Gobiodon, 2 species of Paragobiodon, Cymo sp., Coralliocaris sp., Periclimenes sp. and Alpheus sp. (Fig. 1). 

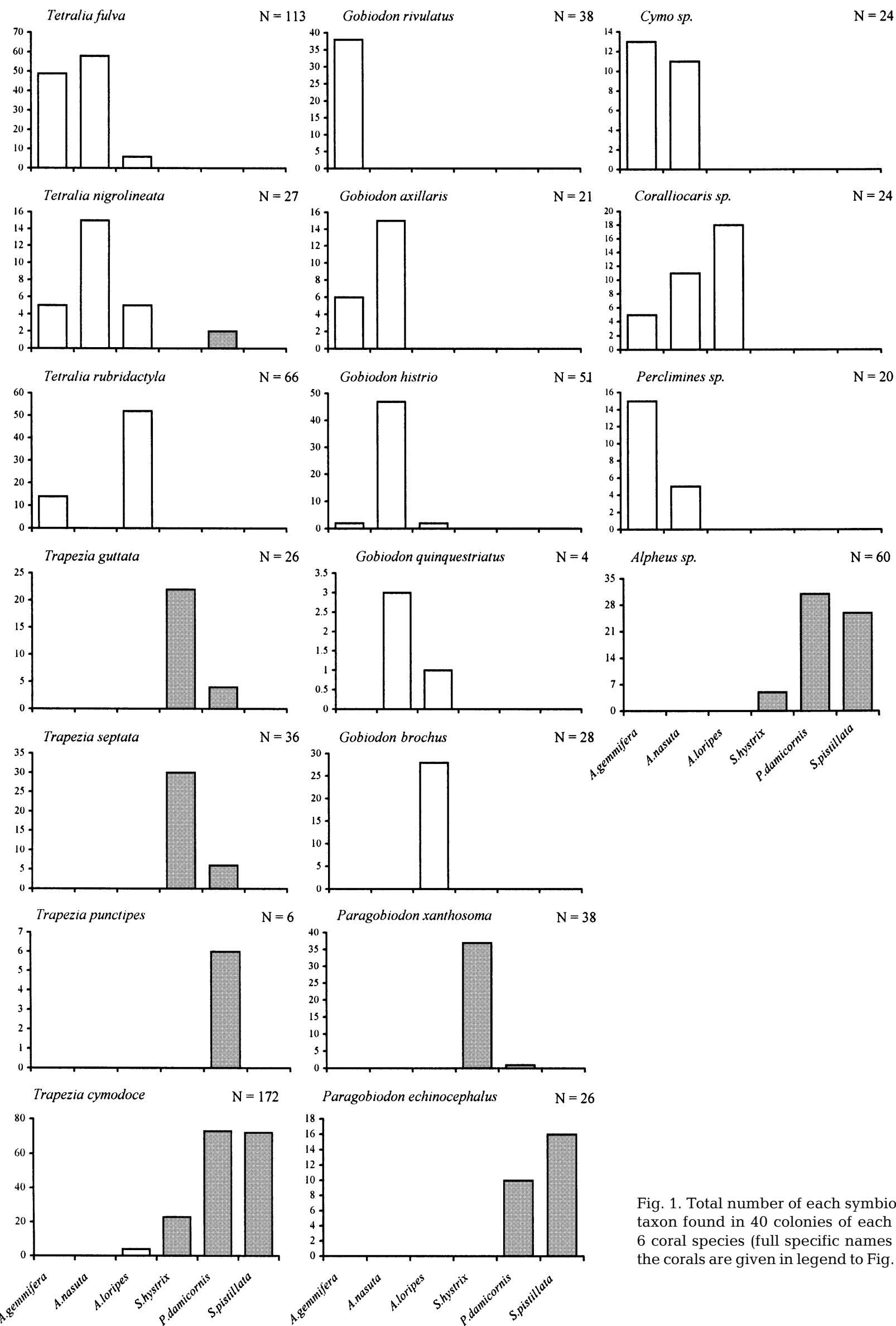

Fig. 1. Total number of each symbiont taxon found in 40 colonies of each of 6 coral species (full specific names of the corals are given in legend to Fig. 2) 
The symbiont assemblages varied greatly between the 6 coral species (Acropora gemmifera, A. nasuta, A. loripes, Pocillopora damicornis, Seriatopora hystrix and Stylophora pistillata). Most notably, there was a clear distinction in the symbiont assemblages between acroporid and pocilloporid corals. Essentially, species of Tetralia, Gobiodon, Coralliocaris and Periclimenes occurred only in acroporid corals, whereas Trapezia, Paragobiodon, and Alpheus species occurred only in pocilloporid corals. Only 2 of the 18 symbiont species identified (Tetralia nigrolineata, and Trapezia cymodoce) were found in colonies from both coral families (Fig. 1). Overall, there were significant differences in symbiont assemblages across all 6 coral species (Pillai's trace $=2.95, F=17.61, \mathrm{df}=90, \mathrm{p}<0.01)$. In the CDA, acroporid corals were clearly separated from the pocilloporids along the primary canonical variate, which accounted for the vast majority $(61.7 \%)$ of the variation in symbiotic assemblages (Fig. 2). The second and third canonical variates, which both accounted for similar proportions of the variance (14.8 and 13.6\%, respectively), clearly revealed variability in the symbiont assemblages among the acroporids and among the pocilloporids, respectively (Fig. 2).

Within the acroporids, the symbiont assemblages of Acropora gemmifera and A. nasuta were relatively similar, whereas $A$. loripes had the most distinct symbiont fauna (Fig. 2a). The predominant crab species found in both $A$. gemmifera and $A$. nasuta was Tetralia fulva, whereas most colonies $(75 \%)$ of $A$. loripes contained only T. rubridactyla (Fig. 1). Cymo sp. crabs and Perclimines sp. shrimps were also common to both $A$. gemmifera and A. nasuta, but were never found in colonies of $A$. loripes. The most prevalent goby, Gobiodon histrio, occupied all 3 Acropora species, but most individuals (92\%) were found in $A$. nasuta. G. rivulatus was the second most commonly occurring goby, but it was found only in A. gemmifera, while $G$. brochus was only found in colonies of A. loripes (Fig. 1).

Among pocilloporid corals, Pocillopora damicornis and Stylophora pistillata were very similar in their symbiotic communities, whereas Seriatopora hystrix had a very distinct symbiont fauna (Fig. 2b). Trapezia cymodoce was prevalent in $95 \%$ of $P$. damicornis colonies and $97.5 \%$ of $S$. pistillata, but were only rarely found in S. hystrix (Fig. 1). Most S. hystrix colonies $(52.5 \%)$ contained the smaller variegated crab, T. septata. Alpheus sp. shrimps were found in all 3 pocilloporid corals, but they were much more abundant in $P$. damicornis and S. pistillata compared to S. hystrix (Fig. 1). The goby Paragobiodon echinocephalus only occurred in $P$. damicornis and $S$. pistillata, whereas Paragobiodon xanthasoma was most commonly found in colonies of S. hystrix (Fig. 1).

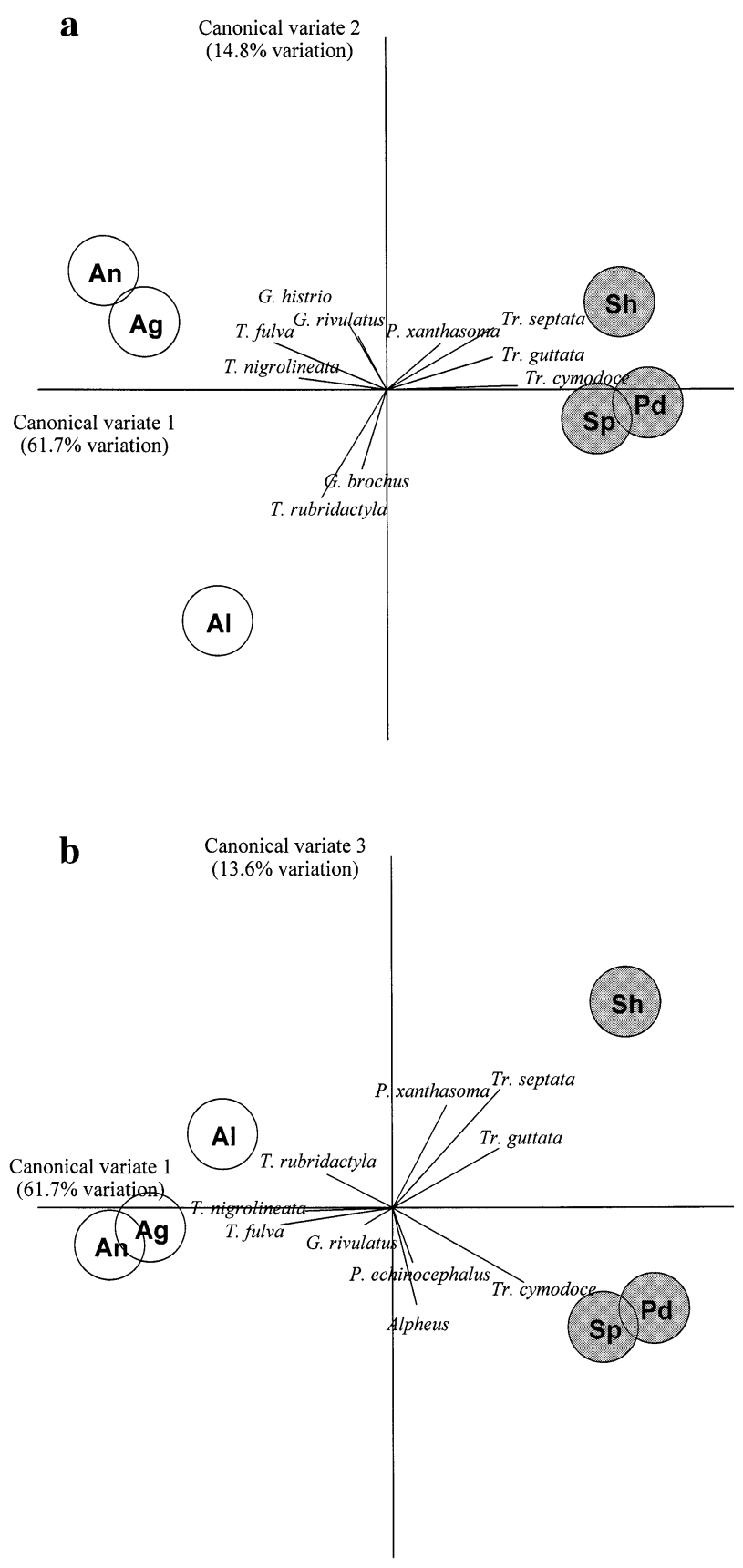

Fig. 2. Canonical discriminant analysis of the community structure of symbionts from 3 Acropora spp. (open circles) and 3 pocilloporid (shaded circles) corals. Canonical Variates 1 and 2 (a) represent $76.5 \%$ of variation and emphasise differences among Acropora spp. corals, Canonical Variates 1 and 3 (b) represent $75.3 \%$ of variation and show differences among pocilloporid corals. Circles plotted represent $95 \%$ confidence limits around the centroids for each coral species. Vectors are structural coefficients of response variables, indicating the relative abundance of each coral symbiont within different coral species. Al: A. loripes; Ag: Acropora gemmifera; An: A. nasuta; Sh: Seriatopora hystrix; Pd: Pocillopora damicornis; Sp: Stylophora pistillata; (full specific names of symbionts as in Fig. 1) 


\section{Feeding trials}

Crown-of-thorns starfish exhibited strong and consistent feeding preferences among corals containing symbiotic fauna. Acropora gemmifera was the most highly preferred coral species, and was the first coral eaten in 9 (of 10) treatment tanks. After A. gemmifera, the starfish tended to consume either $A$. nasuta or $A$. loripes, which were equally preferred (Fig. 3). All acroporid species were significantly preferred over pocilloporid species. Among pocilloporid corals, Seriatopora hystrix was usually eaten first, followed by Pocillopora damicornis and then Stylophora pistillata (Fig. 3). S. pistillata was clearly the least preferred of the 6 coral species and was only rarely (4 of 20 colonies) consumed. The combined ranks for each coral species were significantly different $\left(\chi^{2}=44.17, \mathrm{df}=5, \mathrm{p}<0.01\right)$. Also, the order in which corals were consumed was essentially the same across all replicate tanks ( $W=$ 0.52 , df $=9, \mathrm{p}<0.01$ ), showing strong patterns of feeding preference among Acanthaster planci.

The removal of symbionts from coral colonies did not alter the overall pattern of feeding preferences of Acanthaster planci; within the control tanks, Acropora gemmifera was still the most preferred coral species, and Stylophora pistillata the least preferred (Fig. 3). However, when symbionts were removed, starfish con-
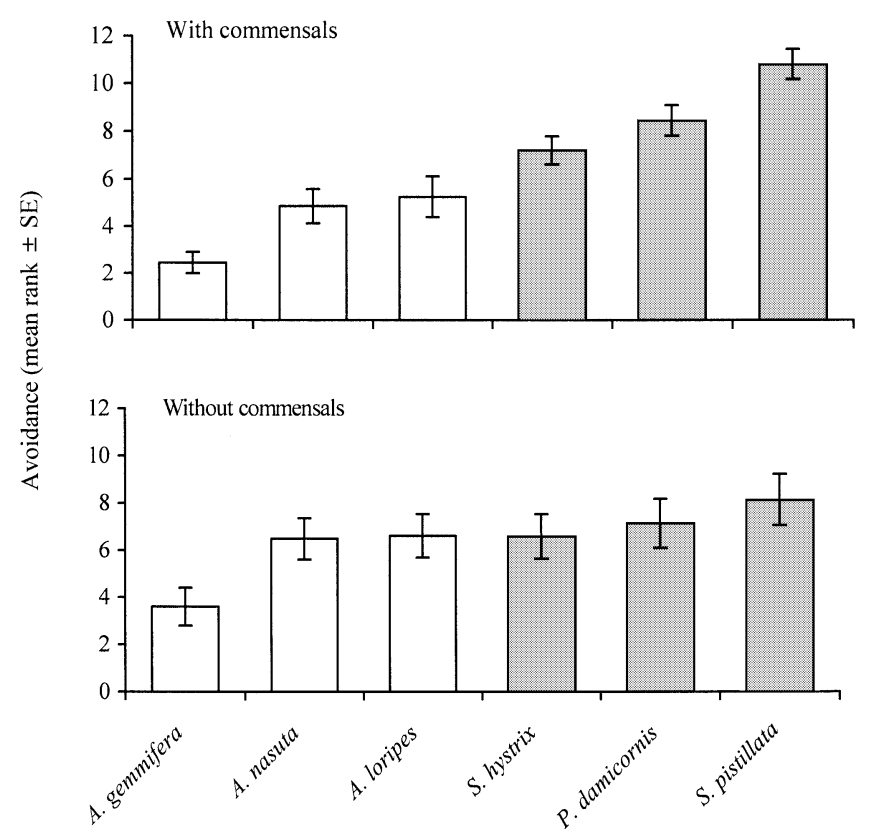

Fig. 3. Acanthaster planci. Variation in the average rank score $( \pm \mathrm{SE})$ for different coral species showing relative avoidance by crown-of-thorns starfish in controlled feeding trials. Feeding preferences of starfish were compared firstly between colonies which contained natural symbiont assemblages (with commensals), and between colonies with symbionts removed (without commensals). For full specific names of corals see legend to Fig. 1 sumed A. nasuta, A. loripes, Seriatopora hystrix and Pocillopora damicornis with apparently equal preference (Fig. 3). The least preferred coral species, S. pistillata, was also eaten far more readily where symbionts had been removed. In tanks where corals contained symbionts, starfish consumed only $20 \%$ (4 of 20 ) of $S$. pistillata colonies, but where symbionts had been removed, starfish consumed $80 \%$ (16 of 20) of the $S$. pistillata colonies. Statistically, there was no significant difference in the combined ranks of the 6 coral species with their symbionts removed $\left(\chi^{2}=4.11, \mathrm{df}=5\right.$, $\mathrm{p}=0.53)$. Moreover, the order in which coral species were eaten differed greatly between replicate tanks ( $W=0.09$, df $=9, p=0.39$ ), further suggesting that starfish had no clear preference for one coral species over another. The feeding preferences of starfish in tanks where all coral symbionts were removed were significantly different from starfish in control tanks ( $W=0.18$, df $=19, \mathrm{p}=0.60)$, suggesting that coral symbionts do have a significant influence on the feeding preferences of $A$. planci.

\section{Manipulating symbionts}

Experimental alteration of the symbiotic fauna in replicate colonies of the same coral species had a great impact on the feeding preferences of crown-of-thorns starfish. Differences in the feeding preferences of Acanthaster planci for Pocillopora damicornis colonies with different symbiont assemblages were highly significant $\left(\chi^{2}=30.74, \mathrm{df}=4, \mathrm{p}<0.01\right)$, and the order in which different colonies were consumed was consistent across replicate tanks ( $W=0.74, \mathrm{df}=9, \mathrm{p}<0.01$ ). The most preferred colonies of $P$. damicornis were those containing either no symbionts or only the goby Paragobiodon echinocephalus. The least preferred colonies were those containing Trapezia cymodoce (Fig. 4). Starfish also tended to avoid colonies containing only Alpheus sp. shrimps, but these colonies were always consumed before those containing T. cymodoce.

In trials using Acropora nasuta, colonies which contained only Gobiodon histrio or Coralliocaris sp. were consumed with equal preference by Acanthaster planci to those colonies that did not contain any symbionts (Fig. 4). However, starfish avoided colonies which contained Tetralia fulva (individually and with other symbionts). Colonies containing all symbionts ( $T$. fulva, Gobiodon histrio and Coralliocaris sp.) were less preferred than colonies containing just T. fulva (Fig. 4). Overall, there was a significant difference in the rank scores for $A$. nasuta colonies in each treatment $\left(\chi^{2}=\right.$ 10.98, $\mathrm{df}=4, \mathrm{p}<0.05)$ and the order in which colonies were eaten was consistent across replicate tanks ( $W=$ 0.52, df $=9$, p <0.01). 


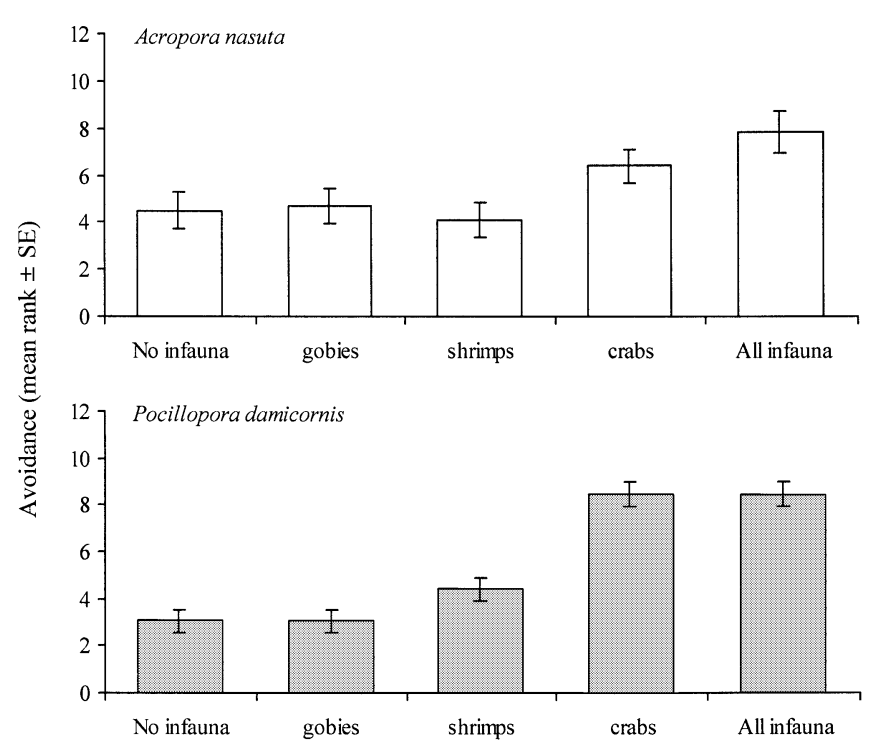

Fig. 4. Acanthaster planci. Variation in the average rank score $( \pm \mathrm{SE})$ for colonies of coral species which contained different symbiont assemblages, showing relative avoidance by crownof-thorns starfish during controlled feeding trials. Feeding preferences of starfish were assessed using Acropora nasuta and Pocillopora damicornis

The influence of coral symbionts on the feeding preferences of Acanthaster planci were similar for both Acropora nasuta and Pocillopora damicornis in so much that colonies containing no symbiotic fauna were significantly preferred over those containing Trapeziidae crabs. Also, colonies of both coral species containing just coral gobies (Gobiodon histrio and Paragobiodon echinocephalus respectively) were equally preferred to colonies containing no symbionts. However, starfish were significantly more selective in trials using $P$. damicornis than in those with A. nasuta ( $W=$ 0.30, df $=19, \mathrm{p}=0.08$ ). Clearly, starfish avoided $P$. damicornis colonies containing Trapezia cymodoce (rank score $=8.5 \pm 0.53 \mathrm{SE}$ ) far more than $A$. nasuta colonies containing Tetralia fulva (rank score $=6.37 \pm 0.72 \mathrm{SE}$ ). In addition, $A$. planci avoided $P$. damicornis colonies containing only Alpheus sp. snapping shrimps, whereas they readily consumed $A$. nasuta colonies containing only Coralliocaris sp. snapping shrimps.

\section{DISCUSSION}

Feeding preferences of crown-of-thorns starfish Acanthaster planci were very apparent from the welldefined and consistent sequence (across replicate tanks) in which it consumed the 6 coral species provided (Acropora gemmifera $>A$. nasuta $=A$. loripes $>$ Seriatopora hystrix > Pocillopora damicornis > Stylophora pistillata). Whereas previous studies have looked only at differences across broad taxonomic groups (e.g. acroporids vs pocilloporids vs poritids: Brauer et al. 1970, Collins 1975, Ormond et al. 1976, De'ath \& Moran 1998), this study is the first to show that $A$. planci has very strong feeding preferences among closely related and morphologically quite similar coral species. This study has also used controlled feeding experiments to largely eradicate many of the factors (such as variation in the size, distribution and abundance of different corals) which may have confounded previous estimates of feeding preference (sensu Moran 1986) and re-affirms that $A$. planci does have strong feeding preferences.

The lack of feeding selectivity among coral species when coral symbionts were removed implies that feeding preferences of Acanthaster planci are determined to a large extent by the differences in the effectiveness with which coral symbionts defend their particular host species (see also Glynn 1982, 1987). Given that feeding selectivity of $A$. planci for corals with their symbionts removed was not significant, any influence that other factors, such as the nutritional value, nematocyst defences, or chemical properties of these corals, may have must be very weak. Even so, A. planci does exhibit strong selectivity for chemical extracts of different coral species (Brauer et al. 1970), which must be caused by differences in either their nutritional value or chemical properties. Similarly, coral nematocysts have been shown to repel A. planci (Barnes et al. 1970). Rather than these findings being contradictory, it is likely that the importance of different factors in determining the feeding preferences of $A$. planci depends greatly on the coral species being considered.

Acanthaster planci consistently prefer Acropora spp. corals over pocilloporids (e.g. Ormond et al. 1976, Keesing 1990, De'ath \& Moran 1998), probably because of differences in the symbionts associated with these corals. In this study, coral symbionts from both $A$. nasuta and Pocillopora damicornis repelled the starfish, but symbionts from the latter were much more effective. Differences in the symbiont assemblages of Acropora spp. versus pocilloporids are consistent across a wide range of coral species (Knudsen 1967, Tsuchiya et al. 1993). Most notably, Acropora species always contain Tetralia spp. crabs, whereas pocilloporids usually contain Trapezia species (Abele \& Patton 1976). The larger size (of both the carapace and chelipeds) of Trapezia species, compared to Tetralia species, may account for the increased efficacy of the former in repelling $A$. planci (Glynn 1987). Moreover, behavioural observations have revealed that Trapezia spp. often attack the thorns of the starfish, breaking them off at the pedicel, whereas Tetralia spp. pinch mainly at the tube feet and, unlike Trapezia, do not cause any lasting damage to the starfish (Glynn 1982, Pratchett et al. 2000). 
Individually, trapeziid crabs were far more effective at repelling crown-of-thorns starfish than either coral gobies or snapping shrimps. Even so, Gobiodon histrio and/or Coralliocaris sp. did contribute to the defence of Acropora nasuta; Acanthaster planci avoided colonies containing all symbionts more strongly than colonies with only Tetralia spp. The synergistic effect of crabs with gobies and/or shrimp in defending $A$. nasuta from the crown-of-thorns may be related to cooperation among symbionts, as proposed by Lassig $(1977,1981)$, whereby the gobies and/or shrimps alert crabs to any potential intruders or corallivores (see also Vannini 1985). This hypothesis is supported from the findings of this study, since neither Gobiodon histrio or Coraliocaris sp. could repel A. planci themselves. In pocilloporid corals, both Trapezia spp. crabs and Alpheus sp. shrimps attack the crown-of-thorns (Glynn 1980) and, as shown in this study, both deter the starfish from feeding on Pocillopora damicornis. Contrary to Lassig's (1981) suggestions, however, there was no synergistic effect of symbionts from $P$. damicornis, perhaps because Trapezia spp. can effectively detect approaching A. planci in small colonies of this coral species and effectively defend colonies without the assistance of other symbionts. There was also no evidence that Paragobiodon echinocephalus contributed to the defence of $P$. damicornis (but see Lassig 1981).

The species of Trapezia found in pocilloporid corals on the Great Barrier Reef include many of the same species (except for a few uncommon endemic species) as those which protect pocilloporids in the eastern Pacific (Garth 1974). Moreover, the effectiveness of Trapezia spp. in repelling Acanthaster planci appears to be consistent across broad geographical boundaries. In Guam, A. planci consume Pocillopora eydouxi and Stylophora mordax 2 to 3 times more if symbionts (including Trapezia spp.) are removed (Glynn 1982). Similarly on the Great Barrier Reef, P. damicornis colonies with symbionts removed were preferred 2.8 times over colonies containing Trapezia spp. (Fig. 4). In Panamá, however, the protection provided by coral symbionts, combined with outbreaks of A. planci, has increased the dominance of pocilloporid corals (Glynn 1974, 1976), whereas on the GBR Pocillopora spp. are commonly consumed during starfish outbreaks (see Keesing 1990, De'ath \& Moran 1998) and Acropora spp. corals virtually always dominate shallow-water coral communities (Done 1982). Increased consumption of pocilloporid corals by A. planci on the GBR may be related to the higher intensity of outbreaks compared to reefs elsewhere in the Pacific, since at higher densities crown-of-thorns starfish increasingly feed on less preferred coral species (reviewed by Birkeland \& Lucas 1990).
Despite the protection provided by coral symbionts, acroporid and pocilloporid corals appear to be among the most highly preferred prey of Acanthaster planci compared to other corals such as poritids and favids, which are strongly avoided (see reviews by Potts 1981, Moran 1986, Birkeland \& Lucas 1990). Poritids also contain symbiotic organisms (Pedum spondyloideum and Spirobranchus giganteus), but rather than preventing $A$. planci from eating their host colony, these organisms enhance the survivorship of only a few adjacent coral polyps which may enable subsequent regeneration of the colony (DeVantier et al. 1986, DeVantier \& Endean 1988). The avoidance of poritids by A. planci is currently ascribed to their low nutritional value and/or the presence of chemical deterrents to feeding (De'ath \& Moran 1998). Controlled experiments, like the one conducted in this study, will be required to resolve why Porites spp. (and faviids) are avoided by A. planci; but whatever the reason(s), it is clear that many coral species are avoided far more than either Acropora spp. or pocilloporids. Therefore, the size, abundance, accessability, the nematocyst or chemical defences, morphology (texture, shape, tissue thickness etc.) or the nutritional value of corals, may be far more important than symbiont defence in determining the overall feeding preferences (across the broad range of different coral species) for $A$. planci.

This study has demonstrated that the feeding preferences of Acanthaster planci, for the 6 coral species examined, are influenced primarily by differences in the symbiotic assemblages of the corals. Although coral symbionts effectively deter starfish from feeding on their host corals, these corals are not totally immune to crown-of-thorns attack, and are readily eaten when coral prey is limited. Consequently, coral symbionts are most likely to influence the feeding preferences and ecological impacts of $A$. planci when starfish are below outbreak densities or coral prey is abundant.

Acknowledgements. This research was funded by the Project AWARE Foundation and the Great Barrier Reef Marine Park Authority. David Pratchett, Ross Thomas and Shaun Wilson assisted with experimental procedures. Terry Hughes, Mark McCormick, Philip Munday and 3 anonymous reviewers provided comments which greatly improved the manuscript. This is contribution number 181 of the Coral Ecology Group at James Cook University.

\section{LITERATURE CITED}

Abele LG, Patton WK (1976) The size of coral heads and the community biology of associated decapod crustaceans. J Biogeogr 3:35-47

Barnes DJ, Brauer RW, Jordan MR (1970) Locomotory response of Acanthaster planci to various species of coral. Nature 228:342-343 
Birkeland C, Lucas JS (1990) Acanthaster planci: major management problem of coral reefs. CRC Press, Boston

Branham JM, Reed SA, Bailey JH (1971) Coral-eating sea stars Acanthaster planci in Haiwaii. Science 172:1155-1157

Brauer RW, Jordan MR, Barnes DJ (1970) Triggering of the stomach eversion reflex of Acanthaster planci by coral extracts. Nature 228:344-346

Chesher RH (1969) Destruction of Pacific corals by the sea star Acanthaster planci. Science 18:280-283

Colgan MW (1987) Coral reef recovery on Guam (Micronesia) after catastrophic predation by Acanthaster planci. Ecology 68:1592-1605

Collins ARS (1975) Biochemical investigation of two responses involved in the feeding behaviour of Acanthaster planci (L.). III. Food preferences. J Exp Mar Biol Ecol 17:87-94

De'ath G, Moran PJ (1998) Factors affecting the behaviour of crown-of-thorns starfish (Acanthaster planci L.) on the Great Barrier Reef. 2. Feeding preferences. J Exp Mar Biol Ecol 220:107-126

DeVantier LM, Endean R (1988) The scallop Pedum spondyloideum mitigates the effects of Acanthaster planci predation of the host coral Porites: host defence facilitation by exaptation. Mar Ecol Prog Ser 47:293-301

DeVantier LM, Reichelt RE, Bradbury RH (1986) Does Spirobranchus giganteus protect Porites from predation by Acanthaster planci: predator pressure as a mechanism of coevolution? Mar Ecol Prog Ser 32:307-310

Done TJ (1982) Patterns in the distribution of coral communities across the central Great Barrier Reef. Coral Reefs 1: 95-107

Garth JS (1964) The Crustacea Decapoda (Brachyura and Anomura) of Eniwetak Atoll, Marshall Islands, with special reference to the obligate commensals of branching corals. Micronesica 1:137-144

Garth JS (1974) On the occurrence in the eastern tropical Pacific of indo-west Pacific decapod crustaceans commensal with reef-building corals. Proc 2nd Int Coral Reef Symp 1:397-404

Glynn PW (1974) The impact of Acanthaster on corals and coral reefs in the eastern Pacific. Environ Conserv 1: 295-303

Glynn PW (1976) Some physical and biological determinants of coral community structure in the Eastern Pacific. Ecol Monogr 46:431-456

Glynn PW (1980) Defense by symbiotic crustacea of host corals elicited by chemical cues from predator. Oecologia $47: 287-290$

Editorial responsibility: Charles Birkeland (Contributing Editor), Honolulu, Hawaii, USA
Glynn PW (1982) Crustacean symbionts and the defense of corals: coevolution on the reef? In: Nitecki MH (ed) Coevolution. University of Chicago Press, Chicago, p 111-178

Glynn PW (1987) Some ecological consequences of coralcrustacean guard mutualisms in the Indian and Pacific Ocean. Symbiosis 4:301-324

Keesing JK (1990) Feeding biology of the crown-of-thorns starfish, Acanthaster planci (Linnaeus). PhD thesis, James Cook University of North Queensland, Townsville

Keesing JK (1993) Influence of persistent sub-infestation density Acanthaster planci (L.) and high density Echinometra mathaei (de Blainville) populations on coral reef community structure in Okinawa, Japan. Proc 7th Int Coral Reef Symp 2:769-779

Knudsen JW (1967) Trapezia and Tetralia (Decapoda, Brachyura, Xanthidae) as obligate ectoparasites of pocilloporid and acroporid corals. Pac Sci 21:51-57

Lassig BR (1977) Communication and coexistence in a coral community. Mar Biol 42:85-92

Lassig BR (1981) Significance of the epidermal ichthyotoxic secretion of coral-dwelling gobies. Toxicon 19:729-735

Moran PJ (1986) The Acanthaster phenomenon. Oceanogr Mar Biol Annu Rev 24:379-480

Ormond RFG, Hanscomb NJ, Beach DH (1976) Food selection and learning in the crown-of-thorns starfish Acanthaster planci (L.). Mar Behav Physiol 4:93-105

Pearson RG, Endean R (1969) A preliminary study of the coral predator Acanthaster planci (L.) (Asteroidea) on the Great Barrier Reef. Fish Notes 3:27-55

Potts DC (1981) Crown-of-thorns starfish — man-induced pest or natural phenomenon? In: Kitching RE, Jones RE (eds) The ecology of pests: some Australian case histories. CSIRO, Melbourne, p 24-86

Pratchett MS, Vytopil E, Parks P (2000) Coral crabs influence the feeding patterns of crown-of-thorns starfish. Coral Reefs 19:36

Tsuchiya M, Yamauchi Y, Moretzsohn F, Tsukiji M (1993) Species composition and some population traits of obligate symbiotic xanthid crabs, Trapezia and Tetralia, associated with bleached corals. Proc 7th Int Coral Reef Symp 1: 56-63

Vannini Z (1985) A shrimp that speaks crab-ese. J Crustac Biol 5:160-167

Yamaguchi M (1986) Acanthaster planci infestations of reefs and coral assemblages in Japan: a retrospective analysis of control effects. Coral Reefs 5:277-288

Zar JH (1984) Biostatistical analysis, 2nd edn. Prentice-Hall, Englewood Cliffs, NJ

Submitted: December 30, 1999; Accepted: August 31, 2000

Proofs received from author(s): March 8, 2001 